Licença CC BY: Artigo distribuído

sob os termos

Creative Commons, permite uso e

distribuição irrestrita em qualquer meio desde que o autor credite a fonte original.

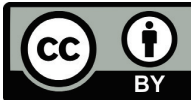

\section{A MENSURAÇÃO DE PERSONALIDADE TURÍSTICA E SUA APLICAÇÃO NA PRÁTICA DOS AGENTES DE MARKETING TURÍSTICO INSTITUCIONAL E SOCIAL NO BRASIL}

\author{
MEASURING TOURIST PERSONALITY AND ITS APPLICATION \\ IN THE PRACTICE OF INSTITUTIONAL AND SOCIAL TOURISM \\ MARKETING AGENTS IN BRAZIL
}

LA MEDICIÓN DE PERSONALIDAD TURÍSTICA Y SU APLICACIÓN EN LA PRÁCTICA DE LOS AGENTES DE MARKETING TURÍSTICO INSTITUCIONAL Y SOCIAL EN BRASIL

\author{
MARCELO DA SILVA SCHUSTER' \\ UNIVERSIDADE FEDERAL DO PAMPA, BAGÉ, RIO GRANDE DO SUL, BRASIL
}

VALÉRIA DA VEIGA DIAS ${ }^{2}$

UNIVERSIDADE FRANCISCANA, SANTA MARIA, RIO GRANDE DO SUL, BRASIL

DATA DE SUBMISSÃO: 29/08/2018 - DATA DE ACEITE: 18/06/2019

\begin{abstract}
RESUMO: Diante da potencialidade turística do Brasil, a questão de pesquisa deste estudo é verificar quais traços de personalidade, existentes nas escalas de mensuração de personalidade turística, estão presentes na descrição de destinos turísticos brasileiros. Com isso, objetiva-se comparar o que foi estabelecido na literatura e sua aplicação para comunicação com o consumidor de turismo no Brasil. Para isso foram estabelecidas três esferas de investigação: i) institucional; ii) comercial; e iii) social. A metodologia incluiu um levantamento a partir de bases de dados internacionais para elencar os instrumentos de mensuração existentes e os traços de personalidade utilizados. Na sequência, foi realizada uma seleção de cidades a serem investigadas por meio do ranking da TripAdvisor em 2017. A análise dos dados pesquisados se deu por meio de análise de conteúdo e uso do software WebQda para organização e classificação dos dados. Os resultados apontam para a importância da personalidade de destino como uma ferramenta de divulgação/ promoção dos destinos turísticos. Contudo, essa ainda é subutilizada no Brasil. Além disso, notam-se ambiguidades entre os traços encontrados e as dimensões das escalas de personalidade de destinos internacionais, apontando para a necessidade de novos estudos sobre o tema.
\end{abstract}

PALAVRAS CHAVE: personalidade de destino, turismo, experiência, pré-compra, marca.

ABSTRACT: In view of the tourism potential of Brazil, the research question of this study was to determine which personality traits, based on tourist personality measurement scales, are present in the description of Brazilian tourist destinations. The aim of this study, therefore,

1 Doutor em Administração pela Universidade Federal de Santa Maria, Santa Maria, Rio Grande do Sul, Brasil. E-mail: marcelo.schuster@gmail.com. Orcid: 0000-0001-7198-1561.

2 Professora Adjunta de Graduação em Administração e Pós-graduação na Universidade FranciscanaUFN, Santa Maria, Rio Grande do Sul, Brasil. Doutora em Agronegócios pela Universidade Federal do Rio Grande do Sul, Porto Alegre, Rio Grande do Sul, Brasil. E-mail: valeria-adm@hotmail.com. Orcid: 0000-00018962-1134. 
is to compare what was established in the literature, and its application for communication with the tourism consumer in Brazil. Three research areas were established: i) institutional; (ii) commercial; and iii) social. The methodology included a survey based on international databases, to list the existing measurement instruments and the personality traits used. The cities to be investigated were selected based on the Trip Advisor ranking 2017. The data collected were analyzed using content analysis, and the software program WebQda was used to organize and classify the data. The results point to the importance of destination personality as a tool for disseminating/promoting tourist destinations. However, this tool is still underutilized in Brazil. In addition, there are ambiguities between the traits found and the dimensions of the international personality scales of destination, indicating a need for further studies on the subject.

KEYWORDS: destination personality, tourism, experience, pre-purchase, brand.

RESUMEN: Ante la potencialidad turística de Brasil la cuestión de investigación de este estudio es verificar qué rasgos de personalidad, existentes en las escalas de medición de personalidad turística, están presentes en la descripción de destinos turísticos brasileños. Con ello, se objetiva comparar lo que fue establecido en la literatura y la aplicación de estos para comunicación con el consumidor de turismo en Brasil. Para ello se establecieron tres esferas de investigación: i) institucional; ii) comercial; y iii) social. La metodología incluyó un levantamiento a partir de bases de datos internacionales para enumerar los instrumentos de medición existentes y los rasgos de personalidad utilizados. En la secuencia se realizó una selección de ciudades a ser investigadas a través del ranking de Trip Advisor en 2017. El análisis de los datos encuestados se dio por medio de análisis de contenido y uso del software WebQ para la organización y clasificación de los datos. Los resultados apuntan a la importancia de la personalidad de destino como una herramienta de divulgación / promoción de los destinos turísticos. Sin embargo, esta todavía es infrautilizada en Brasil. Además, se nota ambigüedad entre los rasgos encontrados y las dimensiones de las escalas de personalidad de destino internacionales. Apuntando a la necesidad de nuevos estudios sobre el tema.

PALABRAS CLAVES: personalidad de destino, turismo, experiencia, pre-compra, marca.

\section{INTRODUÇÃO}

O Brasil é considerado um amplo mercado de turismo em função da diversidade de destinos existentes e capacidade de desenvolvimento desse setor, responsável por cerca de 8\% do PIB no país (UNWTO, 2017). Um estudo do Conselho Mundial de Viagens e Turismo (WTTC) evidencia benefícios do setor para a economia e a geração de empregos no Brasil. Segundo a pesquisa, elaborada pela consultoria britânica Oxford Economics, a contribuição ao Produto Interno Bruto (PIB) cresceu 3,1\% em 2018, totalizando US\$152,5 bilhões (BRASIL, 2019). Além disso, a relevância da aplicação dos preceitos do marketing na investigação do turismo se dá em função de que boa parte do sucesso dos resultados nesta área depende do "combo" produtos e serviços. Neste sentido, fazem parte os aspectos intangíveis do atendimento, bem como a qualidade e o conhecimento a respeito do produto divulgado, ou seja, o local turístico (Kotler, Gertner, Rein \& Haider, 2006; Tsiotsou \& Goldsmith, 2012). Os destinos turísticos enfrentam intensa competição (Hildebrandt \& Isaac, 2015), pois os turistas costumam escolher 
entre destinos com atributos semelhantes, como belas paisagens, amplas praias, comunidades locais amistosas e acomodações de alta qualidade (Usakli \& Baloglu, 2011 apud Soviden, Ladhari \& Chiadmi, 2017).

O conhecimento a respeito dos destinos turísticos envolve a compreensão das potencialidades a serem destacadas e daquilo que pode ser considerado autêntico desta região ou cidade para atrair determinados tipos de consumidores de turismo (Boiteux \& Werner, 2009). O laço emocional entre consumidor e destino turístico pode se estabelecer em função da clara identificação de uma personalização, visto que, com o aumento da concorrência global, os destinos turísticos estão se tornando altamente substituíveis, o que aumenta a complexidade de atrair novos turistas/consumidores (Pike \& Ryan, 2004).

Neste tocante emergem as reflexões e os estudos relacionados à personalização de destinos turísticos e a melhor forma de aproximar consumidores de turismo por meio da disseminação destas características autênticas que refletem a personalidade do destino.

Estudos indicam que uma personalidade de destino distinta pode influenciar as atitudes dos viajantes (Kumar \& Nayak, 2018), suas preferências (D'Astous \& Boujbel, 2007) e as intenções de visitar um destino (Papadimitriou, Apostolopoulou, \& Kaplanidou, 2013; Usakli e Baloglu, 2011). De acordo com Chi et al. (2018), durante a fase de planejamento e pré-compra é quando as percepções dos indivíduos sobre a personalidade de um destino são fatores mais críticos e podem influenciar a tomada de decisões dos viajantes, incluindo o processo de seleção de destinos. Este momento é quando os consumidores de turismo em potencial utilizam a internet como uma ferramenta para a obtenção de informações sobre os possíveis destinos, fundamentando-se em opiniões e experiências de outros turistas (Foley, Fahy \& Ivers 2014).

Segundo os mesmos autores, essas opiniões refletem a construção da marca do local, que serve como um recurso de caracterização e diferenciação entre os locais concorrentes. Ekinci e Hosany (2006) propõem que uma maneira de diferenciar os locais é destacar a personalidade da marca do destino. Corroborando, Chen e Phou (2013) destacam que a personalidade de destino turístico, assim como a personalidade dos indivíduos, representa as características ou os traços mais estáveis e diferenciados a respeito do mesmo. Estes podem ser organizados e avaliados para uma grande quantidade e diversidade de destinos a partir do uso de escalas validadas na literatura.

Apoiados nesta compreensão e considerando o Brasil a partir do contexto de oportunidades turísticas subexploradas no que tange ao Marketing de Destinos turísticos, personalidade e das marcas de destino, é que se desenvolve a proposta deste estudo. O objetivo desta pesquisa é verificar quais traços de personalidade existentes nas escalas de mensuração de personalidade turística estão presentes na descrição dos destinos turísticos brasileiros. Desta forma, objetiva-se verificar a convergência entre a literatura para mensurar personalidade de destinos turísticos e sua aplicação no Brasil em destinos turísticos brasileiros. 
Examinar a personalidade do destino por meio da percepção dos turistas pode ajudar a esclarecer a conexão emocional dos turistas com o destino, bem como capturar a personalidade do destino percebido de turistas reais e potenciais, além de ajudar os destinos a identificar quais traços de personalidade devem ser enfatizados nos esforços de marketing e gestão de destinos para melhorar a experiência dos turistas no destino e aumentar a satisfação dos turistas (Kim \& Stepchenkova, 2017).

A seguir o referencial teórico deste estudo visa apresentar conceitos e literatura relevante acerca do tema personalidade destino, considerando a evolução do tema e sua relação com a personalidade da marca e a marca de destino. Também foram abordados de forma tangenciada, com vistas a criar um plano de fundo para a discussão que se segue, aspectos relacionados à experiência turística e ao processo de compra do consumidor.

\section{FUNDAMENTAÇÃO TEÓRICA}

\section{Personalidade de Destino: a identidade das marcas de destinos turísticos}

O turismo é considerado uma importante atividade econômica, capaz de impulsionar o crescimento de algumas regiões ou países (Rabahy et al., 2008). A globalização e a expansão do mercado do turismo ampliaram as possibilidades de escolhas aos consumidores, o que refletiu na geração de renda desse setor. Segundo Brasil (2018), o turismo é responsável por 6,59 milhões de postos de trabalhos e haverá um crescimento de 1,8\% nesse indicador em 2018, quando o número de empregos chegará a 8 milhões.

O aumento da concorrência entre os destinos sinalizou para a necessidade de busca de diferenciação, por meio da reputação construída, da autenticidade e da estética, constituindo uma personalidade do local (Morgan, Pritchard \& Pride, 2012). Nesta direção, Ekinci e Hosany (2006) destacam que a personalidade de destino é vista como uma metáfora viável para compreender as percepções dos consumidores de turismo e elaborar uma identidade do destino que seja única.

A utilização desse conceito é importante porque as pessoas são atraídas por produtos/locais que julgam ser semelhantes a si mesmo, porque semelhança é considerada emocionalmente gratificante (Moon, 2002). Ao atribuir personalidades positivas a um destino, os viajantes formam atitudes favoráveis (Aaker, 1997; Kumar \& Nayak, 2018) e preferências para esse destino (D'Astous \& Boujbel, 2007), o que pode resultar em alto nível de satisfação (Chen e Phou , 2013; Papadimitriou et al., 2013; Chi, Pan \& Chiappa, 2018).

Posicionar a cidade em um conceito único, mas muito vago (por exemplo, uma cidade dos sonhos) não ajudaria na criação de uma imagem antiga e forte. As imagens podem ter vida curta e seus impactos provavelmente serão eficazes a curto e médio prazo (Souiden, Pons \& Mayrand, 2011). Como 
pessoas e marcas, as cidades precisam desenvolver traços de personalidade que melhor os descrevam (Soviden, Ladhari \& Chiadmi, 2017).

O histórico dos estudos sobre a personalidade de destino remete às pesquisas associadas à personalidade da marca. Aaker (1997) adaptou os traços e as dimensões da personalidade humana do modelo "Big Five" para as marcas. No entanto, somente quase uma década depois Ekinci e Hosany (2006) realizaram uma adaptação da escala da Aaker (1997), propondo a primeira escala para os destinos turísticos. A partir de então se percebeu que os destinos podem ter personalidades que refletem características como sinceridade, emoção e convívio.

Desde então, diversos autores pesquisaram a personalidade de destino (Baloglu, Henthorne \& Sahin 2014; Ekinci \& Hosany, 2006; Murphy, Benckendorff, \& Moscardo, 2007; Murphy, Moscardo, \& Benckendorff, 2007; Sahin \& Baloglu, 2011), destacando sua importância para a diferenciação entre os locais de turismo. Contudo os traços das escalas variaram de um local para outro, como pode ser visto no Quadro 1. 
Rev.Tur., Visão e Ação, v21, n3, p352-372, Set./Dez. 2019 - Balneário Camboriú, Santa Catarina, Brasil

Quadro 1 - Estudos anteriores e dimensões de personalidade de destino

\begin{tabular}{|c|c|c|c|}
\hline Autores & $\begin{array}{l}\text { Quantidade } \\
\text { dimensões }\end{array}$ & Dimensões & Local \\
\hline $\begin{array}{l}\text { Hosany, Ekinci e Uysal } \\
(2006)\end{array}$ & 3 & Sinceridade, emoção/excitação e convívio & $\begin{array}{l}\text { Reino } \\
\text { Unido }\end{array}$ \\
\hline $\begin{array}{l}\text { E|kinci, Sirakaya-Turk } \\
\text { e Baloglu (2007) }\end{array}$ & 3 & Sinceridade, emoção/excitação e convívio & Turquia \\
\hline Usakli e Baloglu (2011) & 5 & $\begin{array}{l}\text { Vibração, sofisticado, competência, } \\
\text { contemporâneo e sinceridade }\end{array}$ & EUA \\
\hline Kumar e Nayak (2014) & 6 & $\begin{array}{l}\text { Cortesia, dinamismo, conformidade, } \\
\text { criatividade, ferocidade e tranquilidade }\end{array}$ & Índia \\
\hline Kumar e Nayak, (2018) & 6 & $\begin{array}{l}\text { Cortesia, vibração, conformidade, } \\
\text { vivacidade, maldade e tranquilidade }\end{array}$ & Índia \\
\hline Lee e Xie (2011) & 4 & $\begin{array}{l}\text { Competência, excitação, sofisticação e } \\
\text { robustez }\end{array}$ & China \\
\hline $\begin{array}{l}\text { Apostolopoulou e } \\
\text { Papadimitrio (2015) }\end{array}$ & 2 & Excitação, sinceridade & Grécia \\
\hline $\begin{array}{l}\text { Papadimitriou, } \\
\text { Apostolopoulou e } \\
\text { Kaplanidou (2015) } \\
\end{array}$ & 2 & Excitação, sinceridade & Grécia \\
\hline Chen e Phou (2013) & 5 & $\begin{array}{l}\text { Excitação, sinceridade, sofisticação, } \\
\text { robustez e contemporâneo }\end{array}$ & Camboja \\
\hline $\begin{array}{l}\text { Gómez Aguilar, Yagüe } \\
\text { Guillén e Villaseñor } \\
\text { Roman (2014) }\end{array}$ & 5 & $\begin{array}{l}\text { Excitação, sinceridade, competência, } \\
\text { sofisticação e robustez }\end{array}$ & $\begin{array}{c}\text { Reino } \\
\text { Unido e } \\
\text { Espanha }\end{array}$ \\
\hline Kilic e Sop (2012) & 4 & $\begin{array}{l}\text { Dinamismo, sinceridade, competência e } \\
\text { sofisticação }\end{array}$ & Turquia \\
\hline $\begin{array}{l}\text { Hultman, Skarmeas, } \\
\text { Oghazi e Beheshti } \\
(2015)\end{array}$ & 6 & $\begin{array}{l}\text { Excitação, sofisticação, atuação efetiva, } \\
\text { confiança, Philoxenia e robustez }\end{array}$ & Tailândia \\
\hline Ye (2012) & 5 & $\begin{array}{l}\text { Sinceridade, excitação, competência, } \\
\text { sofisticação e robustez }\end{array}$ & China \\
\hline Forristal e Lehto (2009) & 4 & $\begin{array}{l}\text { Robustez, sofisticação, sinceridade e } \\
\text { competência }\end{array}$ & EUA \\
\hline Xie e Lee (2013) & 4 & $\begin{array}{l}\text { Robustez, sofisticação, excitação e } \\
\text { competência }\end{array}$ & China \\
\hline Chi et al. (2018) & 3 & Convivialidade, sofisticação e vibração & Itália \\
\hline Klabi (2012) & 3 & Hospitalidade, masculinidade e desagrado & Tunísia \\
\hline Kim e Lehto (2013) & 5 & $\begin{array}{l}\text { Sinceridade, excitação, competência, } \\
\text { sofisticação e robustez }\end{array}$ & $\begin{array}{l}\text { Coréia do } \\
\text { Sul }\end{array}$ \\
\hline $\begin{array}{l}\text { Unurlu e } \\
\text { Küçükkancabaş (2013) }\end{array}$ & 5 & $\begin{array}{l}\text { Sinceridade, excitação, competência, } \\
\text { sofisticação e robustez }\end{array}$ & Turquia \\
\hline $\begin{array}{l}\text { Lim }(2013)^{1} \text { Li }(2009)^{2} \\
\text { Petroski, de Paula } \\
\text { Baptista e Maffezzolli } \\
(2013)^{3} \text { Bilim e Bilim } \\
(2014)^{4}\end{array}$ & 0 & Não separaram em fatores & $\begin{array}{c}\text { 1-EUA; } \\
\text { 2-EUA; } \\
\text { 3-Brasil } \\
\text { 4-Turquia }\end{array}$ \\
\hline
\end{tabular}

Fonte: dados da pesquisa. 


\section{PROCEDIMENTOS METODOLÓGICOS}

Este estudo pode ser classificado como de natureza qualitativa e objetivos descritivos. De acordo com Siqueira (2013), este tipo de pesquisa está presente em estudos com levantamento de dados, opiniões, comportamentos, comparações e relações entre variáveis. De acordo com Foley et al. (2014), as tecnologias e os ambientes existentes na internet expõem o consumidor de turismo às características que lhe permitem personificar o destino turístico, oferecendo antes da viagem as ferramentas para a construção da experiência. Desta forma, optou-se por uma apreciação que contemple uma análise de ferramentas importantes de consulta pública para consumidores de turismo no Brasil.

Para atender os objetivos estabelecidos neste artigo, foram estabelecidas três esferas de investigação: i) institucional (governo); ii) comercial (agência de turismo e publicação); e iii) social (website de divulgação e avaliação turística na internet), que segundo os autores deste estudo, poderiam contemplar diferentes e importantes composições de análise do turismo no Brasil. A escolha destas categorias se deu em função de que se considerou a possibilidade de encontrar descrições muito diferentes ou muito semelhantes. Além disso, julgou-se que cada uma das esferas consideradas possui um objetivo na comunicação e diferente relação com a promoção dos destinos turísticos.

Foram pesquisados, na primeira dimensão, os websites do Governo Estadual de cada local e em alguns casos a página do município ou local; na segunda dimensão, foi escolhido o website de uma agência de viagens (CVC); e para a terceira dimensão, foi utilizado o website de informações e opiniões de conteúdos relacionados ao turismo (TripAdvisor). A pesquisa da esfera institucional se deu inicialmente no website do Governo Federal, posteriormente estadual e municipal. Em alguns casos, identificaram-se informações unicamente no website municipal, sem menção estadual ou federal. As informações foram apresentadas de acordo com o que foi identificado.

A escolha da agência de turismo se deu em função da abrangência nacional e de consultas em relação às "melhores agências de turismo do Brasil". Segundo publicações diversas, que incluem prêmios Top of Mind $(2017 / 2018)^{3}$, e agências que mais faturaram em 2018, a CVC aparece sempre em primeiro lugar. Este foi o critério para escolha da mesma. A TripAdvisor foi escolhida como site de informações de viagens em detrimento de outros concorrentes porque, segundo diversas avaliações, é o website com maior diversidade de informações sobre destinos, hotéis e preços (Blitzsoftwares, 2018).

A coleta de dados incluiu um levantamento a partir de bases de dados internacionais (Web os Science e Scopus) para identificar os estudos anteriores existentes sobre o tema, elencar os instrumentos de mensuração existentes e os traços de personalidade utilizados para pesquisar a personalidade de destino, conforme o Quadro 1 apresentado na seção de referencial teórico.

3 https://viagemeturismo.abril.com.br/materias/veja-os-vencedores-do-premio-o-melhor-de-viagem-eturismo-201718/. 
Após a seleção dos traços, os mesmos foram agrupados por meio de uma abordagem lexical, explicada por Sweeney e Brandon (2006). Esta análise incluiu as características pertinentes e relevantes para o estudo da personalidade, as quais se tornaram uma codificação natural para descrever a personalidade de indivíduo, objeto ou destino.

Com o uso dessa abordagem, os 187 traços encontrados foram agrupados em sinônimos e antônimos com auxílio de dois profissionais, um professor da área de letras, com especialidade em português/inglês e um tradutor autônomo, reduzindo o número de traços de 187 para 38 traços, conforme apresentado no Quadro 2.

Quadro 2 - Traços de personalidade de destino identificadas em estudos anteriores

\begin{tabular}{|l|l|l|l|l|l|}
\hline Acolhedor & Charmoso & Hospitaleiro & Romântico & Agradável & Calmo \\
\hline Pacífico & Alegre & Animado & Divertido & Festivo & Jovem \\
\hline Histórico & Receptivo & Apaixonante & Emocionante & Empolgante & Excitante \\
\hline Fascinante & Autêntico & Aventureiro & Moderno & Badalado & Deslumbrante \\
\hline Chique & Sofisticado & Bonito & Cultural & Dinâmico & Espiritual \\
\hline Místico & Religioso & Orientado para a família & Violento & Rústico \\
\hline Surpreendente & Agitado & Saudável & & & \\
& & & & & \\
\hline
\end{tabular}

Fonte: levantamento realizado pelo autor.

Na sequência foi realizada uma seleção de cidades a serem investigadas por meio do ranking da TripAdvisor com os 10 melhores destinos do Brasil, o qual foi publicado em 2017. Cunningham, Smyth, Wu e Greene (2010) destacam que a TripAdvisor é uma comunidade on-line dominante, em que os consumidores podem compartilhar experiências de viagem. Foram coletados dados secundários a respeito de cada cidade, considerando as três dimensões estabelecidas, conforme o Quadro 3. 
Quadro 3 - Ranking de destinos turísticos brasileiros e local de pesquisa dos dados secundários

\begin{tabular}{|c|c|c|c|}
\hline Ranking dos locais & Institucional & Comercial & Social \\
\hline 1. Rio de Janeiro & $\begin{array}{l}\text { Website governo do estado do Rio de } \\
\text { Janeiro }\end{array}$ & \multirow{10}{*}{$\begin{array}{l}\text { Website da } \\
\text { agência } \\
\text { CVC } \\
\text { Nacional }\end{array}$} & \multirow{10}{*}{$\begin{array}{l}\text { Website do } \\
\text { TripAdvisor }\end{array}$} \\
\hline 2. Gramado & $\begin{array}{l}\text { Website governo do estado do Rio Grande } \\
\text { do Sul }\end{array}$ & & \\
\hline $\begin{array}{l}\text { 3. Jijoca de } \\
\text { Jericoacoara }\end{array}$ & Website governo do estado do Ceará & & \\
\hline 4. Ipojuca & Website governo do estado de Recife & & \\
\hline 5. São Paulo & Website governo do estado de São Paulo & & \\
\hline 6. Foz do lguaçu & Website governo do estado do Paraná & & \\
\hline 7. Florianópolis & $\begin{array}{l}\text { Website governo do estado de Santa } \\
\text { Catarina e do Município de Florianópolis }\end{array}$ & & \\
\hline $\begin{array}{l}\text { 8. Armação dos } \\
\text { Búzios }\end{array}$ & $\begin{array}{l}\text { Website governo do estado do Rio de } \\
\text { Janeiro }\end{array}$ & & \\
\hline 9. Natal & Website governo do estado de Natal & & \\
\hline 10. Salvador & Website governo do estado da Bahia & & \\
\hline
\end{tabular}

Fonte: levantamento realizado pelo autor.

A análise dos dados pesquisados se deu por meio de análise de conteúdo, conforme sugerido por Bardin (2011) e uso do software WebQda para organização e classificação dos dados. A partir da leitura flutuante, primeira etapa da análise de conteúdo, o material descritivo dos websites foi organizado em tabelas e quadros. Em seguida, foi realizada a busca dos traços de personalidade contidos no Quadro 2, com auxílio do software (sinônimos foram considerados na análise).

Por fim, foram verificados como os traços da literatura foram utilizados no material discutido e promocional das três dimensões escolhidas.

\section{ANÁLISE DOS RESULTADOS}

A personificação da marca do destino turístico é uma importante ferramenta para o posicionamento do destino, exercendo uma influência considerável sobre as escolhas e as avaliações dos consumidores de turismo (Del Chiappa \& Bregoli, 2012).

Para a análise dessa ferramenta de diferenciação, os resultados foram apresentados considerando as três dimensões analisadas e a segmentação das cidades por meio de quadros por região do Brasil:

\section{Região Sudeste}

A Região Sudeste teve três cidades entre os 10 melhores destinos turísticos eleitos pelos consumidores que utilizam o site TripAdvisor. Os traços de personalidade de destino encontrados nos websites estão descritos no Quadro 4. 
Rev.Tur., Visão e Ação, v21, n3, p352-372, Set./Dez. 2019 - Balneário Camboriú, Santa Catarina, Brasil

Quadro 4 - Relação entre destinos turísticos da Região Sudeste do Brasil e traços de personalidade encontrados nas dimensões estabelecidas

\begin{tabular}{|c|c|c|c|c|c|c|}
\hline $\begin{array}{l}\text { Destino } \\
\text { turístico }\end{array}$ & $\begin{array}{c}\text { Dimensão } \\
\text { Institucional }\end{array}$ & Quant. & $\begin{array}{l}\text { Dimensão } \\
\text { Comercial }\end{array}$ & Quant. & $\begin{array}{c}\text { Dimensão } \\
\text { Social }\end{array}$ & Quant. \\
\hline $\begin{array}{l}\text { Rio de } \\
\text { Janeiro }\end{array}$ & $\begin{array}{c}\text { Bela, } \\
\text { maravilhosa, } \\
\text { hospitaleira. }\end{array}$ & 3 & $\begin{array}{c}\text { Encantadora, } \\
\text { bela }\end{array}$ & 2 & $\begin{array}{l}\text { Deslumbrante, } \\
\text { fácil, incrível, } \\
\text { apaixonante, } \\
\text { extravagante }\end{array}$ & 5 \\
\hline $\begin{array}{c}\text { Armação de } \\
\text { Búzios }\end{array}$ & Linda & 1 & $\begin{array}{c}\text { Bonita, } \\
\text { animada, } \\
\text { familiar, jovem }\end{array}$ & 3 & $\begin{array}{c}\text { Luxuosa, } \\
\text { deslumbrante, } \\
\text { rústica (robustez) }\end{array}$ & 3 \\
\hline São Paulo & $\begin{array}{l}\text { Nenhum } \\
\text { traço }\end{array}$ & 0 & $\begin{array}{c}\text { Cultural, } \\
\text { efervescente }\end{array}$ & 2 & $\begin{array}{l}\text { Cultural, } \\
\text { diversificada, } \\
\text { diferente, } \\
\text { animada }\end{array}$ & 4 \\
\hline Total & & 4 & & 7 & & 12 \\
\hline
\end{tabular}

Fonte: dados da pesquisa.

A cidade com melhor colocação no ranking escolhido foi o Rio de Janeiro, o principal destaque dado na descrição do destino foi para a sua beleza. Na dimensão institucional, a cidade foi destacada pela hospitalidade e pelas belezas naturais, a descrição não destaca pontos que possam indicar uma personalidade para a cidade. Já na dimensão comercial foram encontrados apenas dois traços de personalidade e outras características genéricas sobre a natureza e as praias. O maior destaque foi dado aos pontos turísticos. Não foram destacadas características da população ou da infraestrutura local. Por fim a dimensão social identificou cinco traços de personalidade, descrevendo a cidade pelas suas festas típicas, como o Carnaval, os monumentos, o Cristo Redentor e a musicalidade da cidade. Não foram destacadas características da população ou da infraestrutura local.

Caso fosse de interesse público ou organizacional utilizar a personalidade de destino para o Rio de Janeiro, considerando os traços encontrados para as três dimensões pesquisadas (institucional, comercial social) e suas respectivas dimensões nas escalas da literatura, a personalidade de destino seria descrita como uma cidade Sofisticada (Chen \& Phou, 2013; Glińska \& Kilon, 2014; Lee \& Xie, 2011 ; Usakli \& Baloglu, 2011 ), Hospitaleira (Ekinci \& Hosany, 2006; Hosany et al., 2006), Vibrante (Kumar \& Nayak, 2014; Usakli \& Baloglu, 2011 ), Franca (sinceridade) (Glińska \& Kilon, 2014), Criativa (Kumar \& Nayak, 2014) e Excitante (Lee \& Xie, 2011 ). ${ }^{4}$

Outro destino investigado na Região Sudeste foi a Armação de Búzios, destino esse com pouca descrição na dimensão institucional, em que foi encontrada somente a característica de beleza (lindo). A dimensão comercial descreve o local a partir de três traços de personalidade, no entanto a descrição centra-se em celebridades internacionais que visitaram o local na década de 1960, bem como nas atividades esportivas presentes na região. Já a dimensão social destaca três traços de personalidade, direcionando para as características de diferenciação social, colocando o local como um refúgio para a elite.

4 Alguns traços foram considerados em mais de uma dimensão, considerando as escalas estudadas. 
Considerando os traços encontrados e as dimensões das escalas, a personalidade Armação de Búzios seria considerada Sofisticada (Chen \& Phou, 2013; Lee \& Xie, 2011; Usakli \& Baloglu, 2011; Ye, 2012), Vibrante (Usakli \& Baloglu, 2011), Excitante (Ekinci \& Hosany, 2006; Hosany et al., 2006; Lee \& Xie, 2011; Apostolopoulou \& Papadimitriou, 2015), Dinâmica (Kilic \& Sop, 2012), Sociável (Ekinci \& Hosany, 2006; Hosany et al., 2006), Excitante (Ye, 2012), Contemporânea (Usakli \& Baloglu, 2011) e Rústica (robustez) (Glińska \& Kilon, 2014; Lee \& Xie, 2011; Ye, 2012).

O último destino eleito na TripAdvisor Choice na Região Sudeste é a cidade de São Paulo. Na dimensão institucional não foi identificado nenhum traço de personalidade, a descrição apresenta apenas as opções turísticas que a cidade tem a oferecer. Na dimensão comercial dois traços de personalidade foram identificados, destacando as múltiplas influências culturais e atrações da cidade como um grande centro metropolitano. Não foram destacadas características da infraestrutura local. Na dimensão social foram identificados quatro traços de personalidade. Além desse, evidenciou-se que o destaque na descrição da cidade concentra-se na culinária e na diversidade dos restaurantes e da população, além das oportunidades de compra. A descrição faz menção ainda ao tamanho da cidade como uma das maiores da América Latina. Não foram destacadas características da infraestrutura local.

São Paulo apresentaria uma personalidade descrita como Franca (sinceridade) (Apostolopoulou \& Papadimitriou, 2015; Hosany et al., 2006; Ye, 2012), Excitante (Ekinci \& Hosany, 2006; Glińska \& Kilon, 2014; Kilic \& Sop, 2012), Dinâmica (Kilic \& Sop, 2012), Contemporânea (Usakli \& Baloglu, 2011) e Vibrante (Kumar \& Nayak, 2014).

\section{Região Nordeste}

A Região Nordeste teve quatro cidades entre os 10 melhores destinos turísticos eleitos pelos consumidores que utilizam o site TripAdvisor. Os traços de personalidade de destino encontrados nos websites estão descritos no Quadro 5. 
Rev.Tur., Visão e Ação, v21, n3, p352-372, Set./Dez. 2019 - Balneário Camboriú, Santa Catarina, Brasil

Quadro 5-Relação entre destinos turísticos da Região Nordeste do Brasil e traços de personalidade encontrados nas dimensões estabelecidas

\begin{tabular}{|c|c|c|c|c|c|c|}
\hline $\begin{array}{l}\text { Destino } \\
\text { turístico }\end{array}$ & $\begin{array}{c}\text { Dimensão } \\
\text { Institucional }\end{array}$ & Quant. & $\begin{array}{l}\text { Dimensão } \\
\text { Comercial }\end{array}$ & Quant. & $\begin{array}{l}\text { Dimensão } \\
\text { Social }\end{array}$ & Quant. \\
\hline $\begin{array}{l}\text { Jijoca de } \\
\text { Jericoacoara }\end{array}$ & $\begin{array}{l}\text { Bela, } \\
\text { maravilhosa }\end{array}$ & 2 & $\begin{array}{c}\text { Sossegada, } \\
\text { aconchegante, } \\
\text { rústica } \\
\text { (robustez). }\end{array}$ & 3 & Rústico & 1 \\
\hline Ipojuca & Zero & 0 & & & Zero & 0 \\
\hline Natal & $\begin{array}{l}\text { Moderna, } \\
\text { alegre, linda, } \\
\text { deslumbrante, } \\
\text { aventureira, } \\
\text { cultural, } \\
\text { hospitaleira, } \\
\text { tranquila }\end{array}$ & 8 & Zero & 0 & $\begin{array}{l}\text { Deslumbrante, } \\
\text { agitada, calma. }\end{array}$ & 3 \\
\hline Salvador & $\begin{array}{c}\text { Belezas } \\
\text { naturais, } \\
\text { cultura } \\
\text { barroca, } \\
\text { neoclássica e } \\
\text { moderna. }\end{array}$ & 6 & $\begin{array}{c}\text { Histórica, } \\
\text { religiosa, } \\
\text { festiva, } \\
\text { arquitetura é } \\
\text { neoclássica, } \\
\text { cultural, bela e } \\
\text { agitada, "terra } \\
\text { da felicidade". }\end{array}$ & & Nenhum traço & \\
\hline Total & & 16 & & 3 & & 4 \\
\hline
\end{tabular}

Fonte: dados da pesquisa.

A cidade de Jijoca de Jericoacoara é destacada por sua beleza na dimensão institucional, que não indicou nenhum outro traço de personalidade. Na dimensão comercial são destacados três traços, no entanto, a maior parte da descrição é genérica e menciona atividades que poderiam ser praticadas em qualquer cidade litorânea. Além disso, são destacados alguns pontos turísticos, festas e o comércio local. Na dimensão social, foi identificado apenas um traço de personalidade e adjetivos deste na descrição. A descrição é genérica, mencionando apenas as praias da região. Não foram destacadas características da população ou da infraestrutura local em nenhuma dimensão.

A personalidade da cidade de Jijoca de Jericoacoara poderia ser descrita como Sofisticada (Chen \& Phou, 2013; Ye, 2012), Tranquila (Kumar \& Nayak, 2014), Da paz (Glińska \& Kilon, 2014), Sociável (Hosany et al., 2006; Kumar \& Nayak, 2014) e Rústica (robustez) (Chen \& Phou, 2013; Glińska \& Kilon, 2014; Lee \& Xie, 2011; Ye, 2012). 
Para a cidade de Ipojuca, a dimensão institucional não proporcionou nenhum traço de personalidade descrevendo o local. A dimensão comercial avaliada não ofereceu descrição do local turístico e na dimensão social não foi identificado nenhum traço de personalidade. A descrição é bastante genérica, mencionando apenas as praias e as atividades na região. Não foram destacadas características da população ou da infraestrutura local. Não foi possível descrever a personalidade da cidade, uma vez que não foram encontrados traços característicos da mesma nos websites.

A cidade de Natal foi descrita com diversos traços de personalidade, destacando características que podem chamar a atenção dos consumidores de turismo. Na dimensão institucional a cidade foi descrita como um local moderno, alegre, lindo, aventureiro, hospitaleiro e cultural. Na dimensão comercial, não foi identificado nenhum traço de personalidade, apenas descrições genéricas sobre natureza, praias e prédios históricos que poderiam estar em outros destinos. Não foram destacadas características da população ou da infraestrutura local. Na dimensão social foram identificados três traços de personalidade, além de atrativos locais. Não foram destacadas características da população ou da infraestrutura local. A cidade de Natal poderia ser descrita com uma personalidade Excitante (Ekinci \& Hosany, 2006; Lee \& Xie, 2011; Ye, 2012), Contemporânea (Chen \& Phou, 2013), Franca (sinceridade) (Chen \& Phou, 2013; Ye, 2012), Sofisticada (Chen \& Phou, 2013; Lee \& Xie, 2011; Usakli \& Baloglu, 2011), Dinâmica (Kilic \& Sop, 2012), Vibrante (Kumar \& Nayak, 2014) e Sociável (Ekinci \& Hosany, 2006; Hosany et al., 2006).

A terceira cidade da Região Nordeste foi Salvador, delineada na dimensão institucional sobre o foco de suas atrações turísticas, destacando suas belezas naturais, as raízes culturais e religiosas, sua arquitetura e diversidade de estilos musicais. A dimensão comercial destacou a mistura de etnias e culturas, a beleza das praias, a diversidade das atrações noturnas. A dimensão social focalizou somente nas opções que a cidade oferece, não trabalhando seus possíveis traços de personalidade.

A personalidade de Salvador, considerando os traços encontrados e as dimensões das escalas, poderia ser descrita como Excitante (Apostolopoulou \& Papadimitriou, 2015; Glińska \& Kilon, 2014; Hosany et al., 2006; Lee \& Xie, 2011), Sofisticada (Chen \& Phou, 2013; Ye, 2012), Vibrante (Usakli \& Baloglu, 2011) e Franca (sinceridade) (Chen \& Phou, 2013).

REgião SUL

A Região Sul teve três cidades entre os 10 melhores destinos turísticos eleitos pelos consumidores que utilizam o site TripAdvisor. Os traços de personalidade de destino encontrados nos websites estão descritos no Quadro 6. 
Rev.Tur., Visão e Ação, v21, n3, p352-372, Set./Dez. 2019 - Balneário Camboriú, Santa Catarina, Brasil

Quadro 6 - Relação entre destinos turísticos da Região Sul do Brasil e traços de personalidade encontrados nas dimensões estabelecidas

\begin{tabular}{|c|c|c|c|c|c|c|}
\hline $\begin{array}{c}\text { Destino } \\
\text { turístico }\end{array}$ & $\begin{array}{c}\text { Dimensão } \\
\text { Institucional }\end{array}$ & Quant. & $\begin{array}{c}\text { Dimensão } \\
\text { Comercial }\end{array}$ & Quant & $\begin{array}{c}\text { Dimensão } \\
\text { Social }\end{array}$ & Quant. \\
\hline Gramado & $\begin{array}{c}\text { Encantadora, } \\
\text { charmosa, } \\
\text { acolhedora, } \\
\text { hospitaleira, } \\
\text { romântica, } \\
\text { alegre, } \\
\text { aconchegante, } \\
\text { mágica, } \\
\text { elegante, bela, } \\
\text { cultural. }\end{array}$ & 11 & $\begin{array}{c}\text { Charmosa, } \\
\text { romântica }\end{array}$ & 2 & $\begin{array}{c}\text { Pitoresca/ } \\
\text { autênti-ca, } \\
\text { surpreenden-te, } \\
\text { encantadora, } \\
\text { divertida e } \\
\text { familiar. }\end{array}$ & 5 \\
\hline $\begin{array}{c}\text { Foz do } \\
\text { Iguaçu }\end{array}$ & $\begin{array}{c}\text { Cultural, } \\
\text { agitada }\end{array}$ & 2 & Bela & 1 & Impressionante & 1 \\
\hline Florianópo- & $\begin{array}{c}\text { Bela, agitada, } \\
\text { tranqüila, } \\
\text { histórica, } \\
\text { cosmopolita e } \\
\text { bucólica }\end{array}$ & 6 & $\begin{array}{c}\text { Linda, } \\
\text { familiar, } \\
\text { tranquila, } \\
\text { divertida, } \\
\text { romântica. }\end{array}$ & 5 & $\begin{array}{c}\text { Moderna, } \\
\text { tranquilo }\end{array}$ & 2 \\
\hline Total & 19 & & 8 & & 8 \\
\hline
\end{tabular}

Fonte: dados da pesquisa.

Na Região Sul, a cidade mais bem colocada na lista foi Gramado ( $2^{\circ}$ lugar no ranking 2016), apresentando em sua dimensão institucional uma cidade pintada como encantadora e romântica, com diversos traços que podem chamar a atenção dos consumidores de turismo que buscam locais hospitaleiros para passar o tempo com seus cônjuges e aproveitar a cultura do local. $\mathrm{Na}$ dimensão comercial, foram evidenciados apenas dois traços de personalidade, e a descrição focada nas opções e atrações para o ano todo. Não foram identificadas características da população ou da infraestrutura local.

$\mathrm{Na}$ dimensão social foram identificados cinco traços de personalidade, além de outros adjetivos, como verdejantes e pequena. A descrição concentra-se essencialmente em atrações da cidade e região e no destaque de emoções que poderão ser vivenciadas pelo turista, tais como "divertir bastante", "vão adorar". Não foram encontradas características da população ou da infraestrutura local.

A personalidade da cidade poderia ser descrita como Sofisticada (Chen \& Phou, 2013; Glińska \& Kilon, 2014; Kilic \& Sop, 2012; Kumar \& Nayak, 2014; Lee e Xie, 2011; Usakli \& Baloglu, 2011; Ye, 2012), Sociável (Ekinci \& Hosany, 2006; Hosany et al., 2006; Kumar \& Nayak, 2014), Franca (sinceridade) (Chen \& Phou, 2013; Glińska \& Kilon, 2014; Hosany et al., 2006; Ye, 2012), Dinâmica (Kilic \& Sop, 2012), Excitante (Chen \& Phou, 2013; Ekinci \& Hosany, 2006; Kilic \& Sop, 2012; Lee \& Xie, 2011; Ye, 2012), Contemporânea (Usakli \& Baloglu, 2011) e Vibrante (Kumar \& Nayak, 2014; Usakli \& Baloglu, 2011). 
Outro destino na Região Sul é a cidade de Foz do Iguaçu, apresentada na dimensão institucional como uma cidade cultural e agitada, favorecendo aqueles que viajam em busca de festas ou com interesse em conhecer novas culturas. Na dimensão comercial foi identificado apenas um traço de personalidade. A definição refere-se em geral às características naturais do local e à proximidade com o Paraguai como centro de compras. Não foram destacados atributos da população ou da infraestrutura local.

Já a dimensão social realça apenas um traço de personalidade, a descrição apresenta as atrações existentes e sua singularidade. Não foram salientadas características da população ou da infraestrutura local. Dessa forma, a descrição da personalidade de Foz do Iguaçu poderia enfatizar os traços de Excitante (Apostolopoulou \& Papadimitriou, 2015; Glińska \& Kilon, 2014; Hosany et al., 2006; Lee \& Xie, 2011), Sofisticada (Chen \& Phou, 2013; Ye, 2012) e Vibrante (Usakli \& Baloglu, 2011).

A terceira cidade da Região Sul foi Florianópolis, realçada na dimensão institucional pelas belezas naturais da cidade, as atrações noturnas, os locais para descanso e passar tempo com a família, além das possibilidades de atividades junto à natureza.

Na dimensão comercial identificaram-se cinco traços de personalidade, além disso, nota-se uma ênfase para as opções de gastronomia local. Descrições genéricas das praias e da "gente bonita" que poderiam estar na descrição de outras cidades. Não foram enfatizadas características da população ou da infraestrutura local. Na dimensão social, foram apontados apenas dois traços de personalidade. A descrição da cidade enfatizou a qualidade de vida dos que vivem na região e no interesse dos consumidores de turismo, além das praias e das atrações culturais.

A personalidade de Florianópolis poderia ser estruturada como Sofisticada (Chen \& Phou, 2013; Lee \& Xie, 2011; Usakli \& Baloglu, 2011; Ye, 2012), Vibrante (Usakli \& Baloglu, 2011), Excitante (Apostolopoulou \& Papadimitriou, 2015; Glińska \& Kilon, 2014; Hosany et al., 2006; Lee \& Xie, 2011; Ye, 2012), Tranquila (Kumar \& Nayak, 2014), Da paz (Glińska \& Kilon, 2014), Franca (sinceridade) (Chen \& Phou, 2013; Hosany et al., 2006; Kilic \& Sop, 2012; Ye, 2012), Sociável (Ekinci \& Hosany, 2006; Hosany et al., 2006; Kumar \& Nayak, 2014) e Contemporânea (Chen \& Phou, 2013). Cabe ressalvar que a cidade de Gramado se sobressai com um grande número de traços de personalidade descritos nos websites social e institucional. Florianópolis também apresentou diversos traços de personalidade enfatizados na dimensão institucional e comercial; por fim a cidade de Natal foi qualificada de forma diversificada na dimensão institucional, apresentando uma série de informações aos consumidores de turismo.

De acordo com Morgan et al. (2004), a criação de uma marca é talvez a mais poderosa arma disponível para os profissionais de marketing de destino para a diferenciação das cidades. Papadimitriou et al. (2015) destacam que, dentro das pesquisas de personalidade e gestão de marcas, uma das áreas ou 
Rev.Tur., Visão e Ação, v21, n3, p352-372, Set./Dez. 2019 - Balneário Camboriú, Santa Catarina, Brasil

ramificações de pesquisa que tem recebido maior atenção é a personalidade de destino, isso em função da possibilidade de que, por meio dela, seja possível identificar e externalizar a vantagem competitiva do local e assim atrair e influenciar os consumidores.

No entanto, na pesquisa realizada nos websites das esferas propostas, pode ser constatado que a personalidade de destino é pouco utilizada pelas instituições e organizações comerciais, sociais e governamentais. Em sua grande maioria, os websites utilizam descrições de traços comuns a qualquer local turístico, como linda, bela, maravilhosa, agitada, cultural.

Desta forma, apesar da grande concorrência entre os destinos turísticos e necessidade de atrair os consumidores, dadas as descrições oferecidas nas três dimensões analisadas, é possível afiançar que estes não apresentam informações suficientes e diferenciadas aos consumidores de turismo para auxiliá-los na fase de pré-consumo e planejamento da viagem.

Neuhofer e Buhalis (2014) ressaltam que os consumidores são ativos e conectados. Swarbrooke e Horner (2007) referenciam que, devido a viagens turísticas envolverem grandes gastos, esses consumidores despendem grande atenção e tempo à fase do planejamento e desta forma Foley et al. (2014) asseguram que as informações fornecidas nos websites são de alta importância, demonstrando assim a carência dos destinos turísticos brasileiros nas ações de marketing.

\section{CONSIDERAÇÕES FINAIS}

A investigação por meio de consulta aos websites, classificados em esfera institucional, social e comercial, permitiu evidenciar que a personalidade de destino, por mais que seja considerada uma ferramenta para a divulgação e promoção dos destinos turísticos, não é utilizada nas descrições e na promoção de destinos turísticos brasileiros. Algumas cidades representaram uma identidade mais claramente definida, manifestada por meio de traços de personalidade (Gramado, Florianópolis e Natal). No entanto, outras respaldam sua descrição em adjetivos genéricos, que não as diferenciam das demais cidades ("cidade bonita", maravilhosa, bela, linda), o que inibe qualquer associação entre personalidade do consumidor e do local e, dessa forma, limitando a relação emocional ou a relação com necessidades específicas. Com a proeminente concorrência entre as cidades, a facilidade de acesso a diversos destinos turísticos e a facilidade de acesso a informações na internet, a padronização na forma de divulgação dos locais turísticos é uma fraqueza. O não uso de uma personalidade de destino pode inibir a diferenciação entre dois locais, fazendo com que o turista não se sinta atraído por nenhum deles ou escolha com base em outros critérios, interferindo assim e sua avaliação pós-compra.

Por outro lado, a utilização da personalidade turística pode criar uma visão singular do local a ser visitado, orientando as expectativas do turista, por exemplo, Gramado foi descrito com traços de personalidade como pitoresca/autêntica, 
surpreendente, encantadora, charmosa, acolhedora, hospitaleira, romântica, divertida e familiar, além de revelar aspectos que possam interessar ao consumidor, torna-se mais atraente na fase de planejamento de viagem do que a cidade de Ipojuca, $4^{\circ}$ lugar no TripAdvisor Choice 2017, porém sem nenhuma descrição de sua personalidade turística. Consumidores de turismo mais aventureiros podem buscar o local sem saber exatamente o que podem encontrar. No entanto, aqueles que preferem planejar atividades, roteiros e custos podem se identificar mais com um destino claramente descrito por sua personalidade.

Desta forma, apesar da personalidade de destino turístico ser caracterizada como uma ferramenta de promoção e diferenciação de locais turísticos, que pode fornecer informações e influenciar as expectativas dos consumidores na fase de planejamento, a mesma ainda é pouco utilizada para a divulgação das cidades brasileiras. E em sua utilização, analisando o enquadramento dos traços encontrados nos websites e das dimensões nas escalas de personalidade turísticas, percebeu-se uma ambiguidade, uma vez que um traço variava de dimensão conforme a escala.

Essa imprecisão dos resultados tornou a possível descrição da personalidade das escalas muito semelhantes, apontando para outro insight interessante identificado nesta pesquisa, a inadequação de muitos traços de personalidade das escalas internacionais à realidade brasileira, apontando para a necessidade de desenvolvimento de uma escala de personalidade de destino turístico para o Brasil.

Cabe ressaltar aqui que uma das limitações deste estudo foi a análise de somente dez cidades, excluindo diversos destinos turísticos conhecidos no Brasil. Este foi um parâmetro escolhido para possibilitar a análise da personalidade turística para as três esferas (institucional, social e comercial). Outra limitação é o uso de dados secundários, pesquisa realizada nos sites de divulgação dos locais, não considerando assim uma pesquisa de opinião direta com os responsáveis pela promoção de cada local ou mesmo a visão dos consumidores de turismo em sua fase de planejamento das viagens.

Como sugestão para futuros estudos, a utilização de outras metodologias de pesquisa pode proporcionar novos insights sobre a utilização da personalidade de destino, assim como clarificar a sua importância, seja por meio da opinião dos divulgadores como pela dos consumidores. Sugere-se ainda o desenvolvimento de instrumentos de pesquisa capazes de representar de forma coerente a realidade brasileira.

\section{REFERÊNCIAS}

Aaker, J. L. (1997). Dimensions of brand personality. Journal of Marketing Research, 34(3), 347-356. doi:10.2307/3151897

Apostolopoulou, A., Papadimitriou, D. (2015). The role of destination personality in predicting tourist behaviour: implications for branding mid-sized urban destinations. 
Rev.Tur., Visão e Ação, v21, n3, p352-372, Set./Dez. 2019 - Balneário Camboriú, Santa Catarina, Brasil

Current Issues in Tourism, 18(12), $1132-1151$.

Arnould, E. J., e Price, L. L. (1993). River magic: Extraordinary experience and the extended service encounter. Journal of consumer Research, 20 (1) 24-45.

Baloglu, S., Henthorne, T. L., e Sahin, S. (2014). Destination Image and Brand Personality of Jamaica: A Model of Tourist Behavior. Journal of Travel e Tourism Marketing, 31 (8), 1057-1070. doi:10.1080/10548408.2014.892468

Bardin, L. (2011). Análise de conteúdo. Lisboa: Edições 70.

Batat, W., Frochot, I. (2014). Towards an experiential approach in tourism studies In: The Routledge Handbook of Tourism Marketing (pp. 109-123): New York: Routledge.

BlitzSoftware. (2018) Booking e TripAdvisor: seu hotel está presente? | Bitz - Bitz Softwares. https://www.bitzsoftwares.com.br/booking-e-tripadvisor-seu-hotel-esta-presentenessas-plataformas/

Brasil, Ministério do Turismo. (2019). Cresce a participação do Turismo no PIB nacional. http://www.turismo.gov.br/\%C3\%BAltimas-not\%C3\%ADcias/12461-cresce-aparticipa\%C3\%A7\%C3\%A3o-do-turismo-no-pib-nacional.html

Brasil, Ministério do Turismo. (2018). Turismo injetou US\$163 bilhões no Brasil em 2017. http://www.turismo.gov.br/\%C3\%BAltimas-not\%C3\%ADcias/ 1 1037-turismo-injetouus\$-163-bilh\%C3\%B5es-no-brasil-em-2017.html

Bilim, Y., Bilim, M. B. (2014). Does a Destination have Personality? Personality and Image Issues of a Destination. Athens Journal of Tourism, 1 (2), 121-134.

Boiteux, B., Werner, M. (2009). Introdução ao estudo do turismo. Rio de Janeiro: Elsevier.

Chen, C.-F., Phou, S. (2013). A closer look at destination: Image, personality, relationship and loyalty. Tourism Management, 36, 269-278. doi:10.1016/j.tourman.2012.11.015

Chi, C. G. Q., Pan, L., \& Chiappa, D. (2018). Examining destination personality: Its antecedents and outcomes. Journal of Destination Marketing \& Management, 9, 149-159. doi:10.1016/j.jdmm.2018.01.001

Cunningham, P., Smyth, B., Wu, G., e Greene, D. (2010). Does TripAdvisor makes hotels better? University College Dublin School of Computer Science and Informatics Report. Acessado em 3 de setembro de 2017 recuperado de http://www.csi.ucd. ie/content/does-tripadvisor-makeshotels-better.

Decrop, A. (2014). Theorizing tourist behaviour. In: The Routledge Handbook of Tourism Marketing (pp. 251-267). New York: Routledge.

Del Chiappa, G., Bregoli, I. (2012). Destination branding development: linking supply-side and demand-side perspectives. Strategic marketing in tourism services, Tsiotsou, R. H., Goldsmith, R. E. (eds.), 51-61 UK: Emerald Group Publishing.

Ekinci, Y., Hosany, S. (2006). Destination personality: An application of brand personality to tourism destinations. Journal of travel research, 45(2), 127-139. 
Ekinci, Y., Sirakaya-Turk, E., e Baloglu, S. (2007). Host image and destination personality. Tourism Analysis, 12(5-6), 433-446.

Foley, A., Fahy, J., e Ivers, A.-M. (2014). Brand experience in tourism in the Internet age In The Routledge Handbook of Tourism Marketing (pp. 140-150): New York. NY: Routledge.

Forristal, L. J., Lehto, X. Y. (2009). Place branding with native species: Personality as a criterion. Place Branding and Public Diplomacy, 5(3), 213-225.

Frochot, I., Batat, W. (2013). Marketing and designing the tourist experience. Oxford: Goodfellow Publishers.

Glińska, E., Kilon, J. (2014). Desirable traits of the city brand personality in the opinion of managers for the promotion of the city government in Poland. Procedia-Social and Behavioral Sciences, 156, 418-423.

Gómez Aguilar, A., Yagüe Guillén, M. J., e Villaseñor Roman, N. (2014). Destination brand personality: An application to Spanish tourism. International Journal of Tourism Research.18(3).

Hildebrandt, T., \& Isaac, R. (2015). The tourism structures in central Vietnam: Towards a destination management organisation. Tourism Planning \& Development, 12(4), 463-478.

Holbrook, M. B., Hirschman, E. C. (1982). The experiential aspects of consumption: Consumer fantasies, feelings, and fun. Journal of Consumer Research, 9(2), 132-1 40.

Hosany, S., Ekinci, Y., Uysal, M. (2006). Destination image and destination personality: An application of branding theories to tourism places. Journal of Business Research, 59(5), 638-642. doi:10.1016/j.jbusres.2006.01.001

Hultman, M., Skarmeas, D., Oghazi, P., e Beheshti, H. M. (2015). Achieving tourist loyalty through destination personality, satisfaction, and identification. Journal of Business Research, 68(11), 2227-2231. doi:10.1016/j.jbusres.2015.06.002

Kilic, B., Sop, S. A. (2012). Destination personality, self-congruity and loyalty. Journal of Hospitality Management and Tourism, 3(5), 95-105.

Kim, S., Lehto, X. Y. (2013). Projected and Perceived Destination Brand Personalities: The Case of South Korea. Journal of Travel Research, 52(1), 117-130. doi:10.1177/0047287512457259

Kim, H., \& Stepchenkova, S. (2017). Understanding destination personality through visitors' experience: A cross-cultural perspective. Journal of Destination Marketing \& Management, 6(4), 416-425. doi:10.1016/j.jdmm.2016.06.010

Klabi, F. (2012). The predictive power of destination-personality-congruity on tourist preference: a global approach to destination image branding. Leisure/Loisir, 36/34), 309-331.

Kotler, P., Gertner, D., Rein, I., Haider, d. H. (2006). Marketing de lugares: como conquistar crescimento de longo prazo na América Latina e no Caribe. São Paulo: Prentice Hall Brasil. 
Rev.Tur., Visão e Ação, v21, n3, p352-372, Set./Dez. 2019 - Balneário Camboriú, Santa Catarina, Brasil

Kumar, V., Nayak, J. K. (2014). Destination Personality Scale Development And Validation. Journal of Hospitality e Tourism Research, 42(1). 1096348014561027.

Kumar, V., \& Nayak, J.K. (2018). Destination Personality:Scale Development And Validation. Journal of Hospitality \& Tourism Research, 42(1), 3-25. doi:10.1177/1096348014561027

LEE, D., XIE, K. (201 1). Cognitive destination image, destination personality and behavioral intentions: An integrated perspective of destination branding. Paper presented at the Graduate Student Research Conference in Hospitality and Tourism, XVI, Houston, USA

Li, X. (2009). An Examination of Effects of Self-Concept, Destination Personality, and SCDP Congruence on Tourist Behavior.Blacksburg, VA. Virginia Polytchnic Institute and State Unversity.

Lim, S. (2013). The Effect of Destination Personality and Self-Destination Congruity on Visitors'intentions. (Dissertação de mestrado) Texas AeM University. Texas, EUA. Available electronically from http://hdl.handle.net /1969.1/149324.

Moon, Y. (2002). Personalization and personality: Some effects of customizing message style based on consumer personality. Journal of Consumer Psychology , 12(4), 313325.

Morgan, N., Pritchard, A., Pride, R. (2004). Destination Branding: Creating the Unique Destination Proposition.Oxford: Elsevier Butterworth-Heinemann.

Morgan, N., Pritchard, A., Pride, R. (2012). Destination Brands: Managing Place Reputation. Oxford: Butterworth-Heinemann.

Murphy, L., Benckendorff, P., Moscardo, G. (2007). Destination brand personality: visitor perceptions of a regional tourism destination. Tourism Analysis, 12(5-6), 419-432.

Murphy, L., Moscardo, G., Benckendorff, P. (2007). Using brand personality to differentiate regional tourism destinations. Journal of travel research, 46(1), 5-14.

Neuhofer, B., Buhalis, D. (2014). Experience, co-creation and technology: Issues, challenges and trends for technology enhanced tourism experiences in The Routledge Handbook of Tourism Marketing (pp. 124-139). New York: Routledge.

Papadimitriou, D., Apostolopoulou, A., Kaplanidou, K. (2015). Destination Personality, Affective Image, and Behavioral Intentions in Domestic Urban Tourism. Journal of Travel Research, 54(3), 302-315. doi: 10.1177/0047287513516389

Petroski, T. A. B., de Paula Baptista, P., Maffezzolli, E. C. F. (2013). Personalidade de Cidades e Marketing de Lugares/Cities' Personality and Place Marketing/Personalidad de Ciudades y Marketing de Sitios. Revista Turismo em Análise, 24(1), 4.

Pike, S., Ryan, C. (2004). Destination positioning analysis through a comparison of cognitive, affective, and conative perceptions. Journal of travel research, 42(4), 333-342.

Rabahy, W. A., Vassallo, M. D., Monti, E. (2008). Crescimento do turismo: análise de aspectos intervenientes e a importância da proximidade dos mercados. Itinerarium, $1(1), 165$. 
Sahin, S., Baloglu, S. (201 1). Brand personality and destination image of Istanbul. AnatoliaAn International Journal of Tourism and Hospitality Research, 22(01), 69-88.

Siqueira, M.A.S. Monografias e Teses: Das normas técnicas ao projeto de pesquisa, 2 ed. Brasília: Consulex, 2013.

Souiden, N., Ladhari, R., \& Chiadmi, N. E. (2017). Destination personality and destination image. Journal of Hospitality and Tourism Management, 32, 54-70. doi:https://doi. org/10.1016/j.jhtm.2017.04.003

Souiden, N., Pons, F., \& Mayrand, M.-E. (2011). Marketing high-tech products in emerging markets: the differential impacts of country image and country-of-origin's image. Journal of Product \& Brand Management, 20(5), 356-367.

Swarbrooke, J., Horner, S. (2007). Consumer behaviour in tourism. New York: Routledge.

Sweeney, J. C., Brandon, C. (2006). Brand personality: Exploring the potential to move from factor analytical to circumplex models. Psychology and Marketing, 23(8), 639663. doi:10.1002/mar.20122

Tsiotsou, R. H., Goldsmith, R. E. (2012). Strategic marketing in tourism services. Oxford: Emerald Group Publishing.

Unurlu, Ç., Küçükkancabaş, S. (2013). The Effects of Destination Personality Items on Destination Brand Image. Paper presented at the Destinasyon Kişiliği Boyutlarının Destinasyon Marka İmajı Üzerine Etkisi]. International Conference on Eurasian Economies.

UNWTO, W. T. O. (2017). UNWTO Tourism Highlights 2015 edition. In. Retrieved from https:// www2.unwto.org/publication/unwto-annual-report-2017

Usakli, A., Baloglu, S. (2011). Brand personality of tourist destinations: An application of self-congruity theory. Tourism Management, 32(1), 114-127. doi:10.1016/j. tourman.2010.06.006

Xie, K. L., e Lee, J.-S. (2013). Toward The Perspective Of Cognitive Destination Image And Destination Personality: The Case Of Beijing. Journal of Travel e Tourism Marketing, 30(6), 538-556. doi:10.1080/10548408.2013.810993

Ye, S. (2012). The impact of destination personality dimensions on destination brand awareness and attractiveness: Australia as a case study. Turizam: znanstveno-stručni časopis, 60(4), 397-409.

\section{Contribuição de cada autor na construção do artigo:}

Marcelo da Silva Schuster: Construção da proposta e escopo do estudo, investigação da literatura, levantamento de dados, pesquisa e análise de dados. Investigação metodológica em estudos na área estudada em busca de uma proposta inovadora para o estudo em questão.

Valéria da Veiga Dias: Construção da proposta e escopo do estudo, investigação da literatura, levantamento de dados e construção da revisão de literatura, pesquisa e análise de dados. Revisão dos aspectos teóricos e atualização do estado da arte. 